\title{
Commercial food advertising on the campus of Ghana's largest University
}

Gideon S. Amevinya ${ }^{1,2}$, MPH, Wilhemina Quarpong ${ }^{1,2}$, MPH, Amos Laar ${ }^{1,2 *}$, Ph.D

${ }^{1}$ Department of Population, Family and Reproductive Health, School of Public Health, University of Ghana, Accra Ghana

${ }^{2}$ House of Mentoring and Research Resources (HM2R). Box LG 1099, University Post Office, Legon, Accra, Ghana.

*Corresponding Author: Amos Laar E-mail alaar@ug.edu.gh

\section{Abstract}

\section{Background}

Non-Communicable Diseases (NCDs) are a leading cause of death globally. NCD mortality attributable to unhealthy food environments (FEs) is significant. Heavy marketing of unhealthy foods is an important contributor to unhealthy FEs.

\section{Aims}

We examined the extent of commercial food advertising, messaging, and signage on the campus of Ghana's oldest and largest university.

\section{Methods}

We cross-sectionally collected data on all sighted advertisements. Advertisements/signage were categorised as food or non-food adverts, and as healthy or unhealthy (if they were food).

\section{Results}

Of 503 advertisements recorded, 238 (47.3\%) were food ads. Advertised food products were categorised as healthy (38.7\%), unhealthy (57.6\%), or other/miscellaneous (3.8\%). The most advertised food product was sugar-sweetened drinks (37.0\%). Different promotional techniques deployed included the use of claim pronouncement, promotional characters, emotional appeal, premium offer, and price promotion.

\section{Conclusions}

The preponderance of unhealthy food advertising on the campus of Ghana's largest university has public health implications. Advertising may influence purchasing behaviour and consumption of unhealthy foods. Publicity and advocacy that motivate development of local policies to regulate various food promotion activities within this, and other Ghanaian food environments are urgently needed. 


\section{Introduction}

The prevalence of non-communicable disease (NCDs), which include type 2 diabetes, hypertension, heart disease and stroke, have reached profound levels and are the leading cause of mortality globally (WHO 2018a). Even though preventable, NCDs are responsible for almost $70 \%$ of all deaths, with most deaths occurring in low- and middle-income countries (WHO 2018b). Obesity, a known risk factor for other NCDs, is increasing at a very fast rate (GBD Obesity Collaborators 2017). In Africa, some 39\% of adults aged 18 years and over are overweight, and 13\% are obese (WHO Regional Office of Africa 2014). This trend is not different from what is observed in children and adolescents in other regions of the world, therefore posing substantial present and future population health risks (Chooi, Ding, and Magkos 2019).

Risk factors such as poor-quality diets have consistently been recognised as important for overweight and obesity (Swinburn et al. 2004, Forouzanfar et al. 2016). These factors are inculcated into daily life partly as a result of various exposures within the physical environment, particularly, the food environment (Glanz 2009). Swinburn and Egger (2002) define the food environment as "the collective physical, economic, policy and socio-cultural surroundings, opportunities and conditions that influence people's food and beverage choices and nutritional status". Accordingly, modifying the food environment toward healthy food choices can be a key approach to preventing obesity and/or excess weight gain.

Modifying the food environment is critical in countries in Africa which are still battling with the consequences of undernutrition, and in addition, experiencing a nutrition transition toward a sedentary lifestyle (Adeboye, Bermano, and Roiiand 2012). Populations are shifting towards intake of more processed foods which are known to have high content of salt, saturated fat, and sugar. This phenomenon is dominant in urban areas where industrialisation and economic development are on the increase (Cockx et al. 2019). New diets, also known as the "western" diet, are available and easily accessible at sources such as fast food joints/restaurants. Most of these food outlets have limited healthy food options. In Ghana, an audit of food shops in a study examining dietary transition in Ghanaian cities recorded energy dense nutrient poor (EDNP) foods, particularly fried foods, processed foods and sugar sweetened beverages, as the most commonly available sold food (Holdsworth et al. 2019).

An important environmental factor that influences dietary habits and intake is exposure to food marketing and advertising practices (Larson and Story 2009, Boyland et al. 2016). Our spaces are heavily saturated with such activities either trying to inform us or persuade us to buy into an idea or product. These practices are used by food marketers in promoting their products through different channels; a prominent form being television advertising (Cairns et al. 2013). Advertising through television has been extensively researched in the developed countries. In the US, food advertising through television accounts for the second largest industry spending (Harris et al. 2002). Evidence from studies consistently report a predominance of marketing on television channels of unhealthy foods such as EDNP foods high in sugar, salt and fat, notable 
among which are sugar-sweetened beverages mostly targeted to children and the youth (Scully et al. 2016, Kelly et al. 2010). These populations are preferentially targeted by marketers partially because of their spending power, their purchasing influences and as potential adult consumers (Cairns et al. 2013). Preliminary findings also from a pilot study assessing the healthiness of foods and beverages advertised on four Ghanaian Television Networks also identified indiscriminate promotion of EDNP foods, especially sugar-sweetened beverages, on children-specific programmes (Kumi and Laar 2020).

In defining foods as "healthy" or "unhealthy", various nutrient profiling approaches exist. Defined by the World Health Organisation (WHO), nutrient profiling is "the science of classifying or ranking foods according to their nutritional composition for reasons related to preventing disease and promoting health" (WHO 2018c). Nutrient profiling models available include the WHO nutrient profiling model (WHO 2015) and the Pan American Health Organization (PAHO) nutrient profiling model (PAHO 2016) which classify foods based on their nutrient composition. The International Network for Food and Obesity/Noncommunicable Diseases Research, Monitoring and Action Support (INFORMAS), classifies foods as healthy if they fall within five core food groups (grains and grain products; vegetables and legumes/beans; fruits; milk and milk products; lean meat, fish, poultry, eggs, nuts, and legumes) (Sally, Janine, and Stefanie 2017). Other existing models include NOVA food classification which classifies food according to the extent and purpose of food processing, rather than in terms of nutrients (Monteiro et al. 2016). The application of these models is useful in different circumstances including enabling governmental bodies to generate nutritionrelated policies to regulate food marketing especially to children, to guide food product labelling, and other nutrition and health claims (Labonté et al. 2018).

Even though it has not gained much consideration in the literature compared to television, other channels like the internet, social media, traditional mobile phone messaging and outdoor advertising (e.g. posters, billboards, free-standing signs, banners, flyers, or stickers) are also used by food marketers (Espinoza, Cevallos, and Tusev 2017). Some researchers have highlighted that these other channels are meant to complement one another to achieve the same goal since marketers have recognized the cumulative effect of multiple media in reinforcing messages to the target audience (Lane and Kevin 2001). Outdoor advertising has the ability to geographically target potential consumers. This is seen as particularly impactful since it is embedded into the physical environment and one cannot avoid being exposed to it easily as compared to that of advertisements on broadcast media platforms like the television or radio (Wilson and Till 2011).

Outdoor advertising as a means of promoting food is heavily placed in close proximity to places like schools, bus stations, roadsides, and other places where they can be repeatedly seen by large numbers of people (Isgor et al. 2016). In a study examining the commercial food landscape around primary schools in Australia, dominating advertised products were products classified as "unhealthy" such as soft drinks, alcoholic beverages, coffee, ice cream, and iced confections (Kelly et al. 2008). Studies also conducted in New Zealand on outdoor advertising 
within the school environment reported $70 \%$ to $80 \%$ of food advertisements to not be in line with national nutritional guidelines (Maher, Wilson, and Signal 2005).

Given that these factors shape dietary intake, interventions to ensure healthy food environments in and around schools, as well as other places people live are required. Recognizing the documented relationship between unhealthy food environments and health, there have been calls for population-based approaches/interventions to promote healthy diets by international bodies like the World Health Organization (WHO). The WHO, during its sixty-third assembly, endorsed a resolution (WHA63.14) urging Member States to restrict unhealthy food marketing to children by taking necessary measures as part of a proposed wider strategy to halt the rise in obesity and other diet-related diseases (WHO 2010). Globally, countries are actively implementing WHA Resolution 63.14, albeit with challenges, though very few are from Africa (WHO 2020b). Only Morocco has fully achieved implementation of NCD progress monitoring indicator \#7C “marketing to children restrictions” (WHO 2020b). Government policies exist in other African countries (e.g. Ghana and Kenya) to restrict exposure and power of promotion of unhealthy foods to or for children across diverse settings. The Ghana Food and Drugs Authority (FDA) requires that products must be registered, and advertisement scripts approved by the FDA before they can be advertised (FDA 2016). A related policy intervention is sugar sweetened beverage taxation. Of note, only South Africa within the African Region has been able to introduce such a tax where it took concerted effort, resources, and alliances of civil society, academia, and government to defeat resistance from food companies (Du et al. 2018). It is predicted that the taxation would lead to a reduction in energy intake by about $36 \mathrm{Kj}$ per day and a reduction in obesity by 3.8\% in South African adults (Manyema et al. 2014). Morocco attempted, but was forced to repeal its sugar sweetened beverage tax in November 2018 prior to implementation in January 2019 due to pressures from the agri-food industry (Bazza 2018).

In Ghana, misleading marketing of EDNP foods predominate in urban settings (Bragg et al. 2017). There are however, no published studies on outdoor food advertising within any Ghanaian setting-despite some research looking at obesogenic environment in some schools (Alangea 2014, Fernandes et al. 2017). Adult-focused studies examining promotional techniques used in food advertisements are scant. Our literature search reveals little research has been done focusing on young adult population (Jernigan et al. 2017, Hafez 2004); most of which have analysed promotional techniques used to advertise alcoholic drinks and tobacco products. This study therefore examined the nature and extent of commercial food advertising on the campus of Ghana's largest University.

\section{Methods}

\section{Study design and site}

This study was observational, using a descriptive cross-sectional design. Purposive sampling was used in a tertiary level educational setting, the University of Ghana. This campus (Fig.1) is situated at Legon, a highly urbanised community in Accra, Ghana's capital city. The university is the premier and largest of the 13 public universities in Ghana with a student 
population of over 38,000. Other child-serving units (e.g. the University Primary and Junior High Schools) are present on the University's campus.

\section{Summary of field procedures}

Prior to data collection, the research team obtained details of the university geographical boundaries from the university Physical Development and Municipal Services Directorate (PDMSD) to familiarise themselves with the study site.

Data collection was conducted through direct observation during school hours (Monday-Friday 7:00 am to 5:00 pm) from April to May 2019. This period ensured survey activities were conducted whiles full academic session was ongoing. This was done by two trained field data collectors together with a supervisor, all of whom had a minimum educational qualification of a bachelor's degree.

In this study, advertisement was defined as any image of branded food products/companies displaying information that aimed at creating awareness about a product/service. This included different formats such as billboards, posters, banners, free-standing signs, painted buildings, and digital/LED signs. Even though store signs were excluded, those signages meant for store identification having a product/company logo also displayed on them were considered as advertisement. Non-food advertisements were also collected as part of this study.

Data collectors, together with the team supervisor, independently inspected and coded all advertisement within a selected location outside the University boundaries during a pretesting exercise. We used a mobile application (Open Data Kit-ODK) installed on a mobile tablet device with a camera and GPS function during data collection. A data collecting template, a Standard Outdoor Advertising Audit tool adopted from the INFORMAS Outdoor Advertising Protocol (Kelly et al. 2010), was programmed onto the mobile device. This approach allowed a concurrent recording of images, as well as their descriptive information (i.e. type of advert, size of advert, form of advert, location of advert, product and brand name, promotional character, premiums offer) and GPS location for each sighted advertisement.

Reliability estimate was calculated from the pretesting data to assess advertisement coding reliability. This was done by comparing data collected between the two data collectors for interrater reliability and also comparing with the supervisors for validity, using the field supervisor data as the reference (the 'gold standard'). Some disagreements (23\%) were identified in the data collected during pretesting among team members, hence, a repeated training was organised during which discrepancies were discussed and attended to. Actual data collection was conducted after $85 \%$ inter-rater reliability was achieved between data collectors.

During the actual data collection, all sites and streets within the university were surveyed during a onetime visit to each site. Data collectors navigated the study site by walking and scanning through the streets and facilities on the university campus, recording all visible advertisements present. 


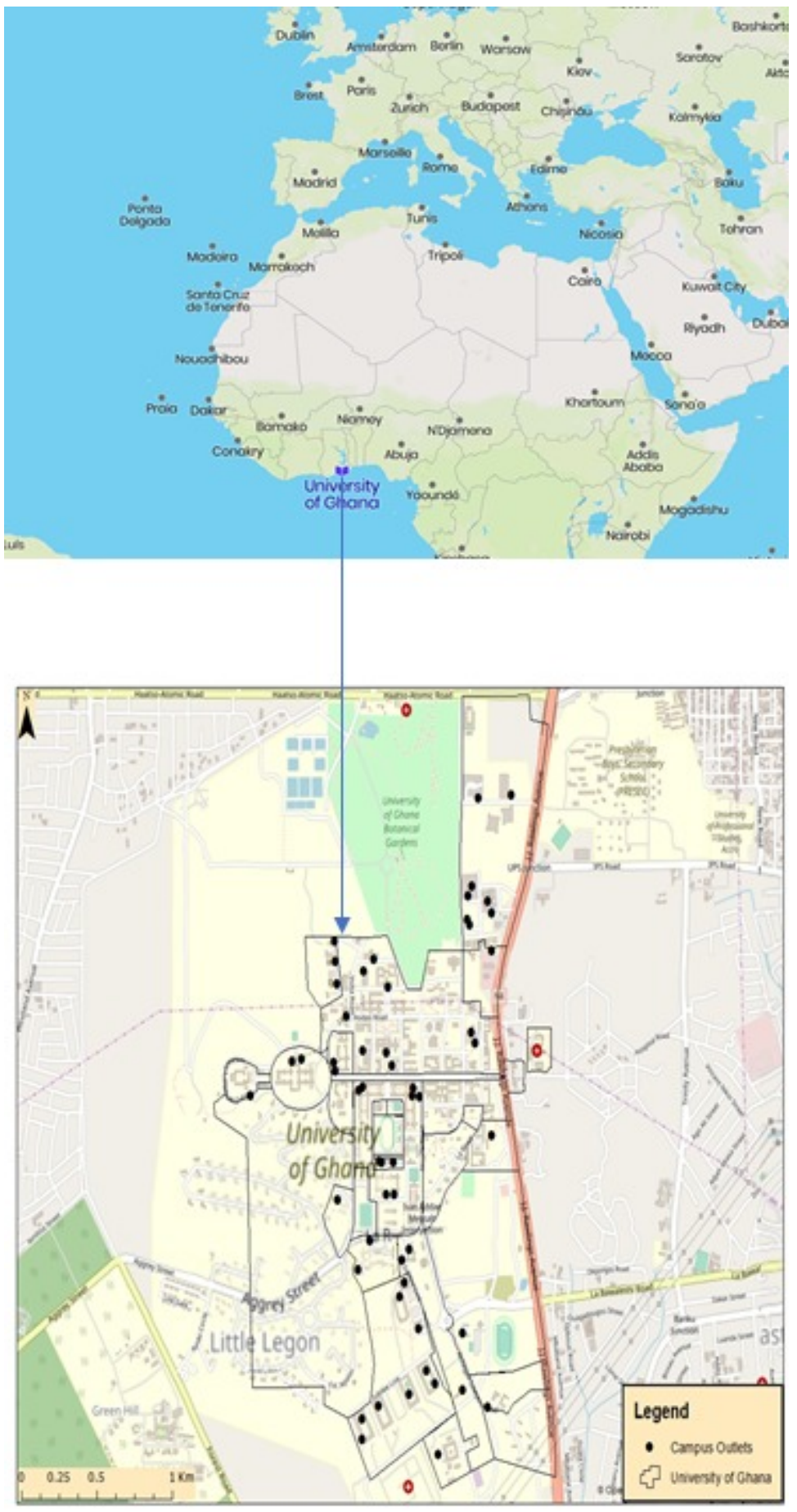

Fig, 1: Map showing the location of study area.

\section{Food product categorisation}

Food products depicted in advertisements were assigned to three major food groups: Healthy, Unhealthy and Other/Miscellaneous, based on a food classification system adopted from INFORMAS (Sally, Janine, and Stefanie 2017) but refined to include branded foods sold in Ghana. Classification was completed after field data collection. This classification approach was also used in previous research involving outdoor advertising (Kelly et al. 2008). The field 
supervisor together with a nutrition expert with knowledge on marketed products within Ghana categorised all food advertisements, ensuring consistency across all coded advertisements. For food advertisements without sufficient information to enable classification, an additional category — unspecified was created and assigned to those advertisements.

\section{Ethics}

Ethical approval to conduct this study was obtained from the Ghana Health Services Ethics Review Committee (GHS-ERC019/01/19).

\section{Data Analysis}

Descriptive statistics from univariate analyses were conducted using IBM SPSS Statistics for Windows version 21 to assess the prevalence and relative proportion of each food advertisement attribute. Categories of food products advertised were compared using percentages.

\section{Results}

Overall, all 503 outdoor advertisements recorded in this study were distributed in the area within the university but mostly at places where the university populace lives.

\section{Characteristics of food advertisements}

Of the 503 ads, $47.3 \%$ (238/503) were of food, a majority of which were located at food outlets (75.2\%) and along road networks (15.1\%) - See Fig.2. The most prevalent medium of display of these advertisements was posters (47.5\%). Store merchandising (which includes foodbranded refrigerators, bins, chairs, umbrellas) was a distant second - See Fig.3. There were proportionately more (58\%) small ( $>$ A4 but $<1.3 \mathrm{~m} \times 1.9 \mathrm{~m}$ ) size advertisements - See Fig.4.

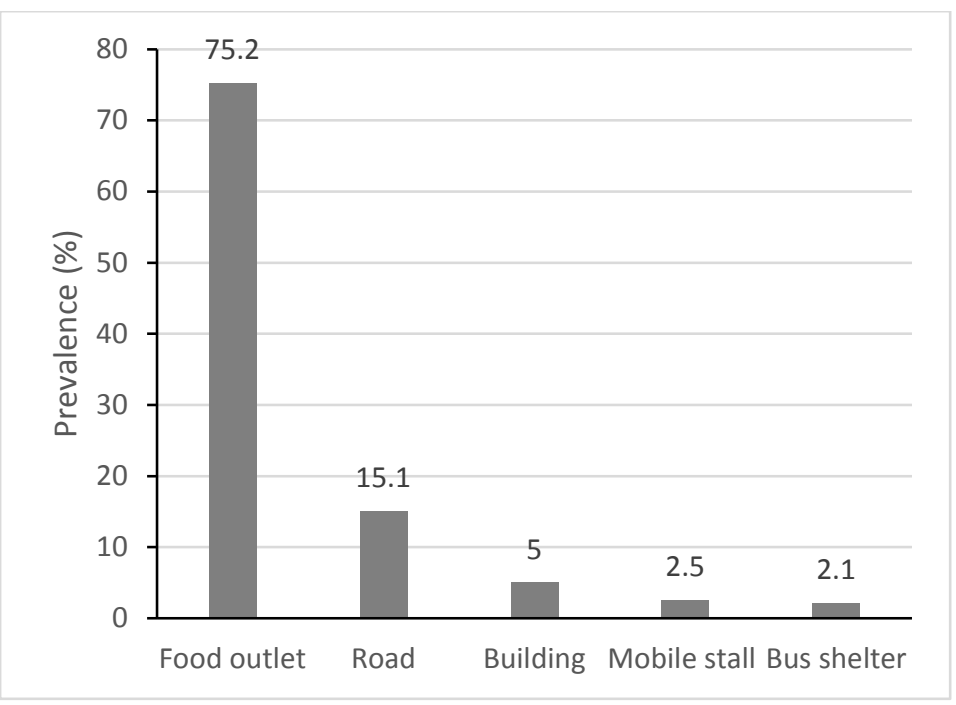

Fig.2. Food advertisements by setting 


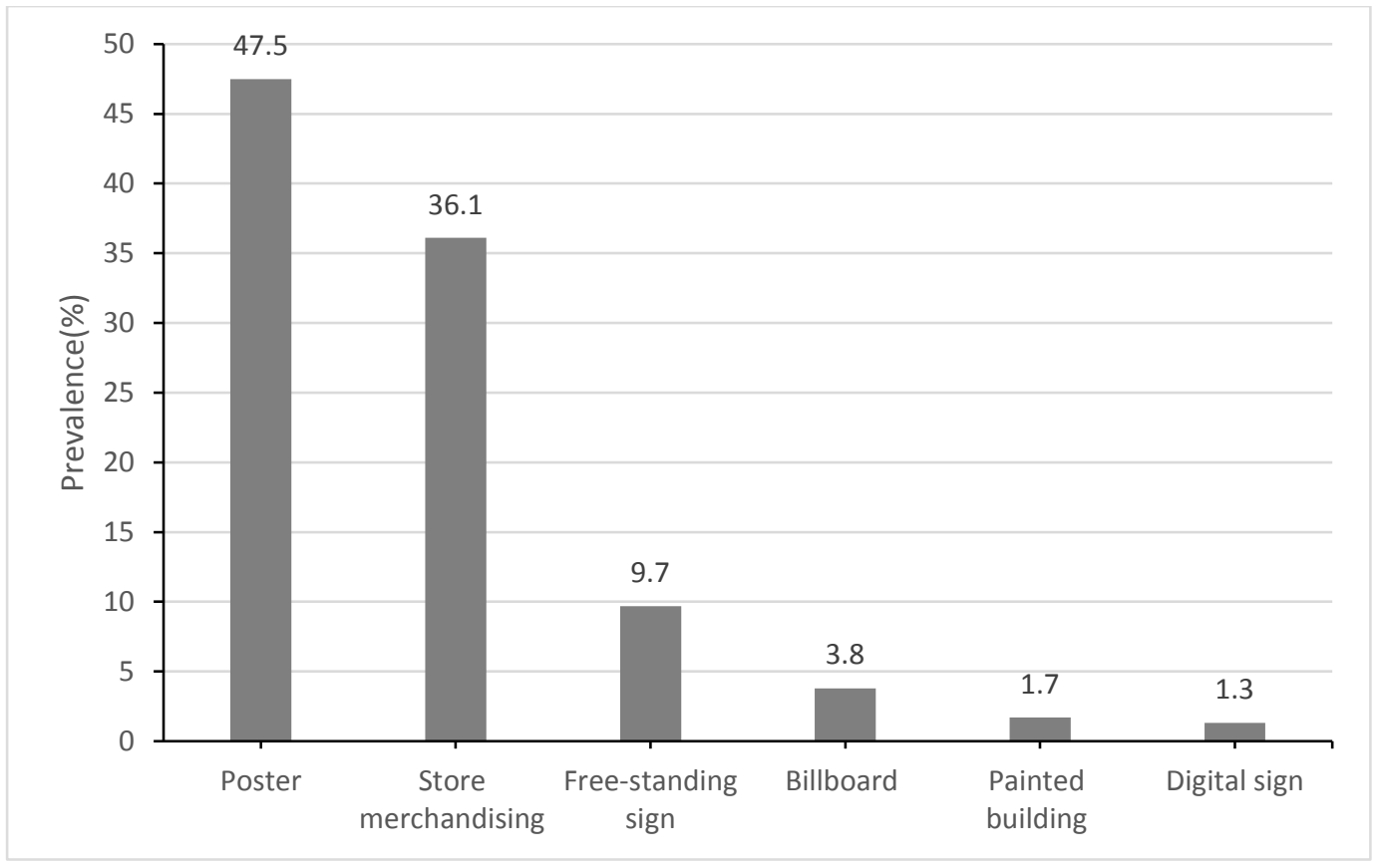

Fig.3. Food advertisements by advertisement medium

\section{Advertisements by food category}

The distribution of major food categories is shown in Fig.4. Of the food advertisements identified, nearly $60 \%$ were classified as unhealthy food; $38.7 \%$ were healthy foods and $3.8 \%$ classified as other/miscellaneous.

The most advertised food product was sugar-sweetened drinks (37.0\%). A small number of bottled water advertisements were observed (4.6\%) See Table 1.

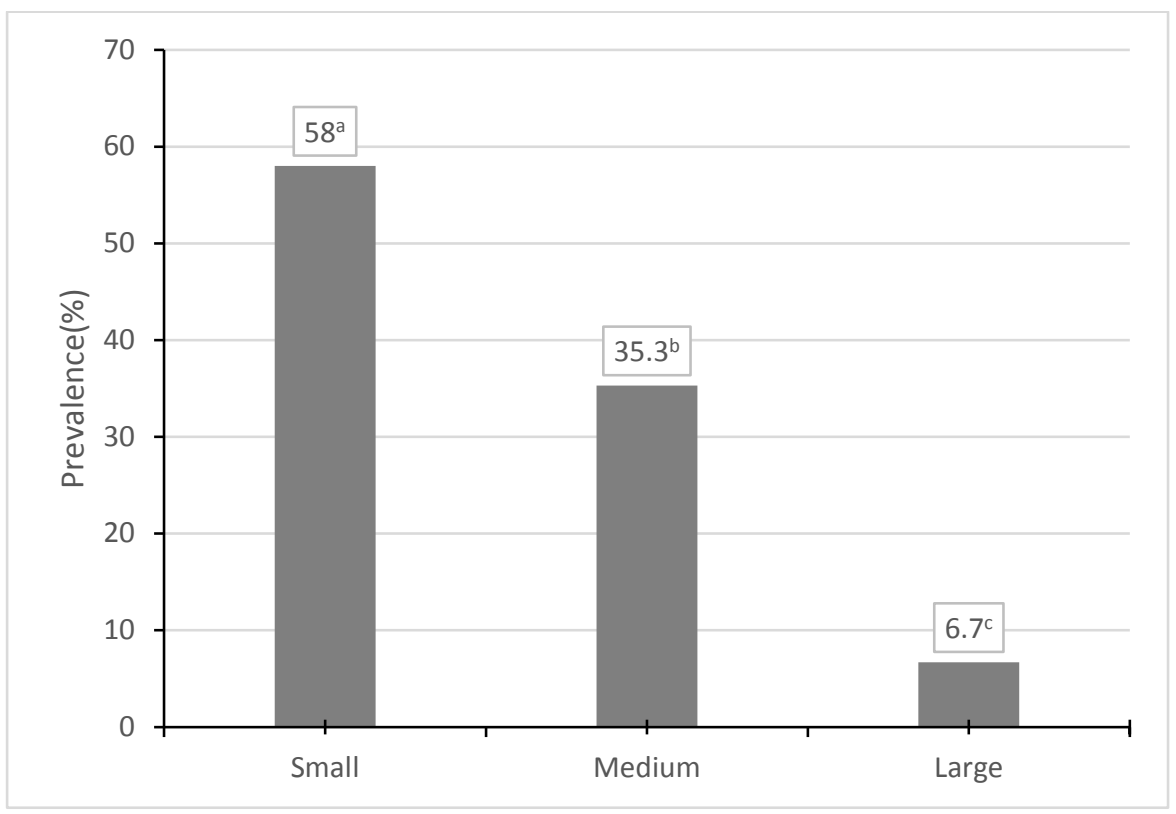

${ }^{a}(>A 4$ but $<1.3 m \times 1.9 m) ;{ }^{b}(>A 4$ but $<1.3 m \times 1.9 m),{ }^{c}(>2 m \times 2.5 m)$ 
Fig.4. Food advertisements by size

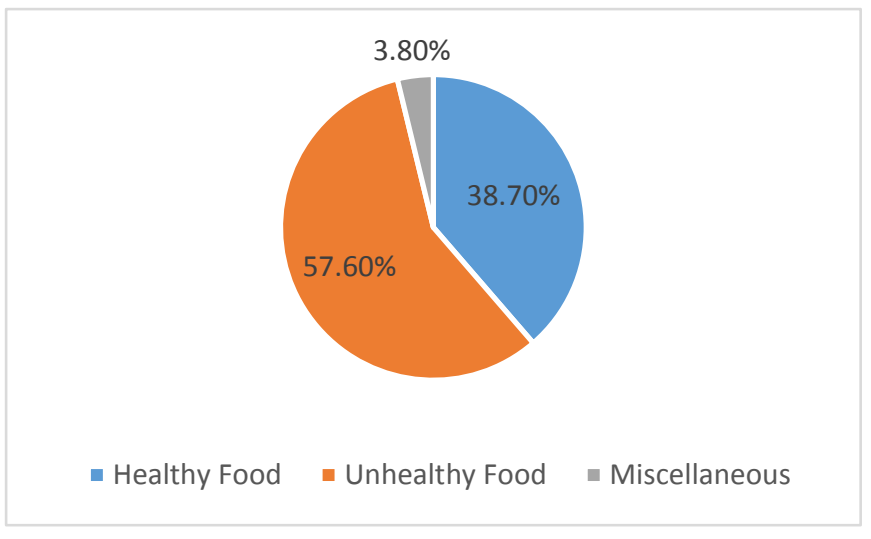

Fig.4. Distribution of food advertisements by food category

\section{Promotional techniques used in food advertisements}

Of the food advertisements, promotional techniques were identified for 131/238 (55\%) of them. Claim pronouncement was the most prominent (92/131) of all promotional techniques, including sensory based (39/92); health and nutrition (31/92); and "made from natural products” (15/92). See Fig. 5.

As Fig. 5 also shows, 39/131 promotional techniques made use of promotional characters. Two-thirds of these promotional characters depicted an adult-based actor (26/39); others included child-based actors (3/39) and cartoon/licensed based characters (10/39)

Aside from claim pronouncement and use of a promotional character, the other types of promotional techniques recorded were emotional appeal (17/131) and price promotion (10/131). Premium offer was the least commonly used technique recorded (2/131).

\section{Discussion}

Research on outdoor advertising of food and beverage products is gaining attention in the public health literature, with most findings from studies conducted in developed countries. To the best of our knowledge, the present study is the first to examine outdoor food advertising in any tertiary institution in Ghana. Our findings indicate that outdoor advertising of products is an ongoing

marketing activity within the university's space and young adults could be influenced. Food advertisement accounts for almost half (47.3\%) of all outdoor advertisement identified and the majority (57.6\%) of these foods were unhealthy; $37.0 \%$ being sugar sweetened beverages. This is of public health concern, given that exposure to food advertisements has been shown to influence food choices, brand preferences, and dietary behaviour (Sadeghirad et al. 2016, Cairns et al. 2013, Smith et al. 2019). 
Table 1: Distribution of advertised food products $(n=238)$

\begin{tabular}{|c|c|c|}
\hline Food products & Frequency & Percentage \\
\hline \multicolumn{3}{|l|}{ Healthy food category } \\
\hline Cereals: without added fat, sugar or salt & 16 & 6.7 \\
\hline Low sugar and high fibre breakfast cereals & 5 & 2.1 \\
\hline $\begin{array}{l}\text { Fruits and fruit products without added sugars or } \\
\text { salt }\end{array}$ & 14 & 5.9 \\
\hline $\begin{array}{l}\text { Milks and yoghurts and their alternatives }(\leq 3 g \\
\text { fat } 100 \mathrm{~g})\end{array}$ & 34 & 14.3 \\
\hline Oils high in mono- or polyunsaturated fats & 12 & 5.0 \\
\hline Bottled Water & 11 & 4.6 \\
\hline \multicolumn{3}{|l|}{ Unhealthy food category } \\
\hline Flavoured/fried instant rice and noodle products & 12 & 5.0 \\
\hline Sweet breads, cakes, muffins, sweet buns & 1 & 0.4 \\
\hline $\begin{array}{l}\text { Meat and meat alternatives (processed/preserved } \\
\text { in salt) }\end{array}$ & 1 & 0.4 \\
\hline Savoury snack foods (added salt or fat) & 3 & 1.3 \\
\hline $\begin{array}{l}\text { Fruits and fruit products with added sugars, fats } \\
\text { or salt -- fruit juice/drinks }<98 \% \text { fruit. }\end{array}$ & 8 & 3.4 \\
\hline $\begin{array}{l}\text { Milks and yoghurts and their alternatives }(>3 g \\
\text { fat/100g) }\end{array}$ & 9 & 3.8 \\
\hline Ice cream and iced confection & 10 & 4.2 \\
\hline Chocolate and candy & 1 & 0.4 \\
\hline Fast food & 4 & 1.7 \\
\hline $\begin{array}{l}\text { Sugar-sweetened drinks: soft drinks, energy } \\
\text { drinks, powdered flavour additions (e.g. sweetened } \\
\text { tea or coffee powders), }\end{array}$ & 88 & 37.0 \\
\hline \multicolumn{3}{|l|}{ Miscellaneous } \\
\hline $\begin{array}{l}\text { Recipe additions (including soup cubes and } \\
\text { seasonings) }\end{array}$ & 8 & 3.4 \\
\hline Tea and coffee (unsweetened) & 1 & 0.4 \\
\hline Total & 238 & 100 \\
\hline
\end{tabular}

Universities are mostly densely populated and clearly advertising of products in these high dense areas will be of great value to food marketers. The prevalence of advertised unhealthy foods within the university environment, whether intentionally or inadvertently, means high exposure of these advertisements to students and pupils who have the autonomy to make dietary decisions, and, in the Ghanaian context, have high purchasing power. Unhealthy food advertising within this environment can also influence the children and adolescents who live in residential facilities for faculty, staff, and their families or visit the university community (Sadeghirad et al. 2016). Though they may not have purchasing power, they have pester power (Nash and Basini 2012). These unhealthy advertisements may defy all effort to encourage 


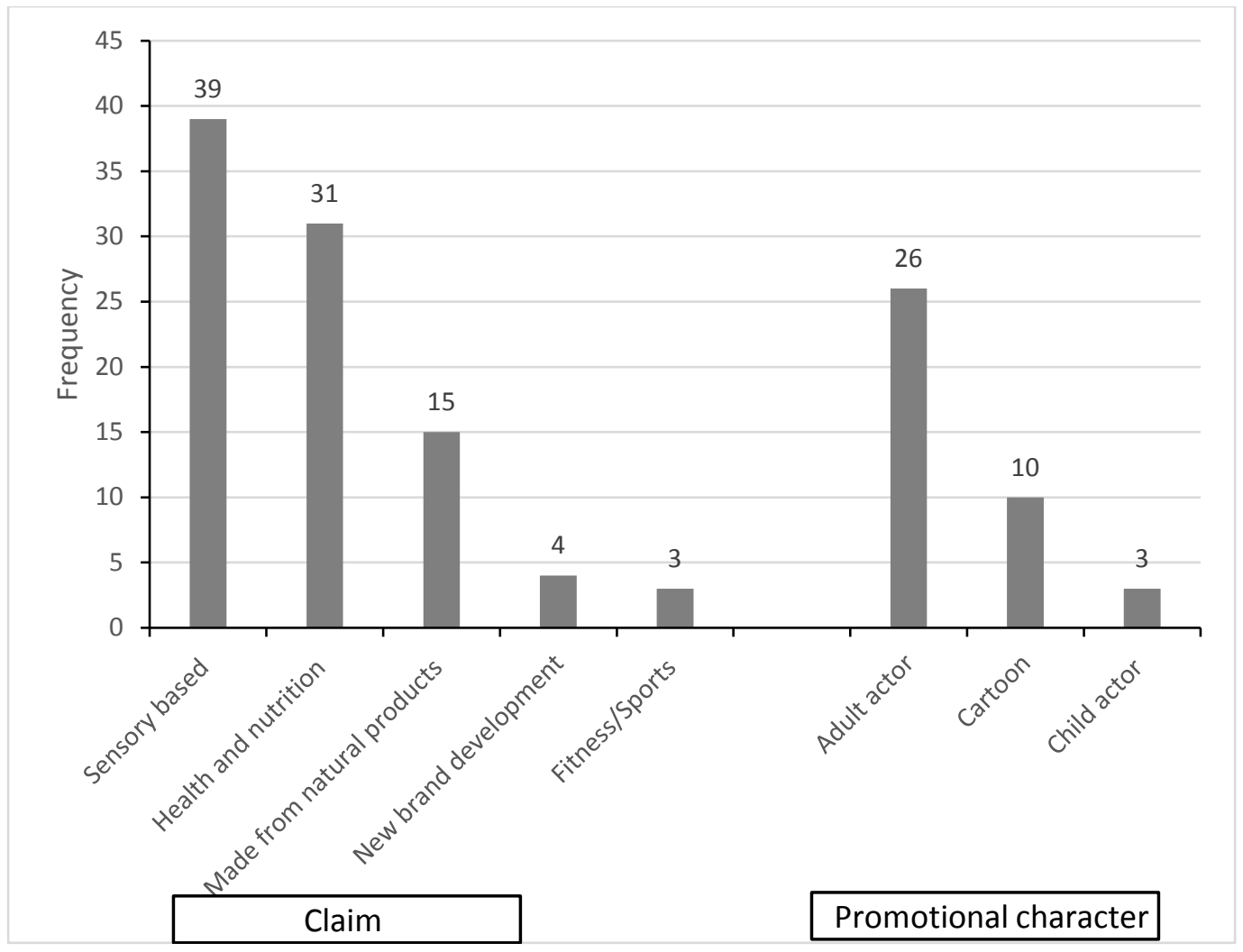

Fig.5. Claims and Promotional characters featured on food advertisement $(\mathrm{n}=131)$

healthy eating, and therefore potentially contributing to poor diet and subsequently, diet related-NCDs.

Our finding of sugar-sweetened beverages, particularly soft drinks been the most advertised food product (37.0 \%) supports previous research by Green et al. (2018), reporting sugarsweetened beverages as the most commonly marketed food product in urban Africa (Ghana inclusive). Recently, a study examining the determinants of dietary behaviour in Ghana also found food advertising to be one of the factors that influenced unhealthy dietary behaviour in Ghanaian cities (Holdsworth et al. 2019).

This state of unhealthy food advertising does not align with global nutrition recommendations on food advertisement (WHO 2010). Sugar-sweetened soft drinks have been identified as a probable causal factor in weight gain and obesity (Osei-Assibey et al. 2012). This led to Member States of the World Health Organisation (Ghana inclusive), in 2010, to endorse a resolution (WHA63.14) to reduce the impact of marketing of unhealthy foods (WHO 2010). Clearly, our finding shows a noncompliance to this recommendation. In addition, the high level of sugar-sweetened beverage advertisement contradicts the global nutrition guidelines recommending that consumption of free sugars and fats should be less than $10 \%$ and $30 \%$ of total energy intake respectively (WHO 2020a). The pervasive nature of unhealthy food advertisement within the university, therefore, is an indication of inadequate action on the part of the university authorities and also on the part of government in enforcing these recommendations. 
Exposure to food advertisement in this study primarily occurs at food shops (75.2\%). The high occurrence of advertisements at food shops speaks to the importance of these food shops in not just serving as a place for acquiring food, but also as marketing units deployed by food vendors and marketers to increase exposure to their products. In the US, Isgor and colleagues (Isgor et al. 2016) found $73 \%$ of food shops having advertisements in and around them. Such settings give consumers an opportunity to immediately act upon the advertisement message and subsequently indulge in the purchase and consumption of the product being advertised (Beleva et al. 2019). Students frequently visit these food outlets to make food purchases, and food products depicted in advertisements at food shops were usually the same products sold in the food shops. These findings therefore suggest that food shops within the University community are potential places to consider when implementing food policies aimed at ensuring a healthy food environment within the University.

The use of different promotional techniques in promoting products was evident in this study. Such techniques have been shown to make advertising communication very effective (Hebden, King, and Kelly 2011). To date, research on techniques used in food advertisement (mostly on television) have mainly been child-focused with accumulating evidence on the impact of specific marketing techniques on children (Cairns et al. 2013, Sadeghirad et al. 2016, Hebden, King, and Kelly 2011). Our literature search revealed little research focusing on the young adult population, most of which have analysed promotional techniques used to advertise alcoholic drinks and tobacco products (Jernigan et al. 2017, Hafez 2004). We recorded the use of claim pronouncement - mainly sensory based and health/nutrition claims. Unlike for children, the influence of such techniques on young adults' food consumption patterns or weight has not been well assessed (Freeman et al. 2016).

Additionally, as reported in previous studies (Hebden, King, and Kelly 2011, Jenkin et al. 2014), our study reveals the use of fun and fantasy in advertising food products. Young adults are undergoing personal identity formation and can be receptive to marketing depicting any desirable character trait or mood, especially those with emotional appeal. Such "image marketing'" sells not only a tangible product, but also image attributes and symbols of consumption (Pechmann et al. 2005).

Research has shown that exposure to food advertisement describing the sensory attributes leads to craving for such food by initiating thoughts and desire for the advertised food product even if one has no need for food at that moment (Moore and Konrath 2014). Claims on product advertisements have been demonstrated to be influential mostly among children (Chhabra and Singha 2017) and have also been reported to likely inflate perceived healthfulness of nutritionally poor foods (Nestle and Ludwig 2010). In Ghana, the Food and Drugs Authority, being aware of the implications of the effect of claims, especially when used in promoting unhealthy food products, have guidelines to ensure advertisement of foods are conducted in a manner which is responsible and does not mislead consumer (FDA 2013). Some of these advertisements adhere to the health claim regulatory guidelines in that they mention the actual component (vitamin or mineral) that brings about the health benefit, but others were exaggerated. More than half of the advertisements that had health claims promised 
improvement of well-being. This is misleading as well-being is a broad area that involves a balance of mental, social and physical well-being.

One positive finding of this research is the existence of a policy regulating the placement of advertising within the university (University of Ghana, 2012). This policy prohibits placement of advertisements at academic areas like faculty and departmental buildings, lecture halls and other main avenues like the university's main entrance. However, this policy had no focus on the kind of foods permitted to be advertised.

Data reported here are only representative of the University of Ghana Legon campus. Given that the results of this study point to a large quantity of unhealthy product advertisements, we recommend further investigation to understand the extent and nature of this phenomenon in other institutions, particularly child serving institutions, if possible, at different time intervals.

\section{Conclusions}

The preponderance of unhealthy food advertising on the campus of Ghana's largest university has public health implications. Advertising may influence purchasing behaviour and consumption of these unhealthy foods, perhaps even setting the stage for poor life-long food habits. Publicity and advocacy that motivate development of local policies to regulate various food promotion activities within this and other food environments in Ghana are urgently needed. We recommend that within the current advertisement regulations the university authorities incorporate restrictions on unhealthy food advertisement. Food outlets present an ideal setting where such changes can be easily implemented because they will want to retain their right to be located on campus. Also monitoring systems should be put in place to ensure food vendors and food marketers within the university adhere to these regulations.

\section{Declarations}

Availability of data and materials

Study dataset available for deposition in a public repository if needed

\section{Competing interests}

All authors declare no competing interests

\section{Funding}

The study was partly funded by the Measurement, Evaluation, Accountability, and Leadership Support for NCDs prevention - MEALS4NCDs Project (IDRC Grant Number: 108983-001)

\section{Authors' contributions}

AL conceived the manuscript idea. GA and AL implemented the study. GA drafted the manuscript. AL and WQ critically reviewed the draft manuscript. All authors approved the final version.

\section{Acknowledgements}

We are grateful to the organisers of the World Public Health Nutrition Congress 2020 to present this study. The manuscript is an expanded version that was presented (virtually) at the Congress. 


\section{References}

Adeboye, Bridget, Giovanna Bermano, and Catherine Roiiand. 2012. "Obesity and its health impact in Africa: a systematic review." Cardiovascular Journal of Africa, 23 (9):512.

Alangea, Deda Ogum. 2014. "Determinants of obesity among basic school pupils in the GaEast Municipality, University of Ghana."

Bazza, Tarek. 2018. "Morocco to Cancel Increased Soft Drink Taxes Under Manufacturer Pressure." Morocco World News.

Beleva, Yuliyana, James Russell Pike, Stephen Miller, Bin Xie, Susan L Ames, and Alan W Stacy. 2019. "Share of advertising voice at the point-of-sale and its influence on atrisk students' use of alternative tobacco products." Nicotine and Tobacco Research, 21 (7):903-910.

Boyland, Emma J, Sarah Nolan, Bridget Kelly, Catrin Tudur-Smith, Andrew Jones, Jason CG Halford, and Eric Robinson. 2016. "Advertising as a cue to consume: a systematic review and meta-analysis of the effects of acute exposure to unhealthy food and nonalcoholic beverage advertising on intake in children and adults." The American Journal of Clinical Nutrition, 103 (2):519-533.

Bragg, Marie A, Tamara Hardoby, Natasha G Pandit, Yemi R Raji, and Gbenga Ogedegbe. 2017. "A content analysis of outdoor non-alcoholic beverage advertisements in Ghana." BMJ Open, 7 (5).

Cairns, Georgina, Kathryn Angus, Gerard Hastings, and Martin Caraher. 2013. "Systematic reviews of the evidence on the nature, extent and effects of food marketing to children. A retrospective summary." Appetite, 62:209-215.

Chhabra, Aprajit, and Bibek Singha. 2017. "Persuasive marketing techniques used by companies to attract children." TRANS Asian Journal of Marketing \& Management Research (TAJMMR), 6 (1):39-44.

Chooi, Yu Chung, Cherlyn Ding, and Faidon Magkos. 2019. "The epidemiology of obesity." Metabolism, 92:6-10.

Cockx, Lara, Liesbeth Colen, Joachim De Weerdt, and Gomez Y Paloma. 2019. "Urbanization as a driver of changing food demand in Africa: Evidence from ruralurban migration in Tanzania." JRC Technical Reports:1-51.

Du, Matthew, Aviva Tugendhaft, Agnes Erzse, and Karen J Hofman. 2018. "Focus: Nutrition and Food Science: Sugar-Sweetened Beverage Taxes: Industry Response and Tactics." The Yale Journal of Biology and Medicine, 91 (2):185.

Espinoza, Melissa, Norman Cevallos, and Aleksandar Tusev. 2017. "Changes in media consumption and its impact in modern advertising: a case study of advertising strategies in Ecuador." INNOVA Research Journal, 2(6), 120-135.

FDA. 2016. Guidelines for the Advertisement of Foods. FDA/FID/GL-AD/2016/01. Accra Ghana. Available at https://fdaghana.gov.gh/images/stories/pdfs/downloads/food\%20guidelines/REVIE WED\%20GUIDELINES\%20FOR\%20THE\%20ADVERTISEMENT\%20OF\%20FOODS-28-116-FINAL-FINAL.pdf

Fernandes, Meenakshi, Gloria Folson, Elisabetta Aurino, and Aulo Gelli. 2017. "A free lunch or a walk back home? The school food environment and dietary behaviours among children and adolescents in Ghana." Food Security, 9 (5):1073-1090.

Forouzanfar, Mohammad H, Ashkan Afshin, Lily T Alexander, H Ross Anderson, Zulfiqar A Bhutta, Stan Biryukov, Michael Brauer, Richard Burnett, Kelly Cercy, and Fiona J Charlson. 2016. "Global, regional, and national comparative risk assessment of 79 behavioural, environmental and occupational, and metabolic risks or clusters of risks, 
1990-2015: a systematic analysis for the Global Burden of Disease Study 2015." The Lancet, 388 (10053):1659-1724.

Freeman, Becky, Bridget Kelly, Stefanie Vandevijvere, and Louise Baur. 2016. "Young adults: beloved by food and drink marketers and forgotten by public health?" Health Promotion International, 31 (4):954-961.

GBD Obesity Collaborators. 2017. "Health effects of overweight and obesity in 195 countries over 25 years." New England Journal of Medicine, 377 (1):13-27.

Glanz, Karen. 2009. "Measuring food environments: a historical perspective." American Journal of Preventive Medicine, 36 (4):S93-S98.

Green, Mark, Rebecca Pradeilles, Amos Laar, Hibbah Osei-Kwasi, Nicolas Bricas, Nathaniel Coleman, Senam Klomegah, Milkah Njeri, Akua Tandoh, Robert Akparibo, Paula Griffiths, Elisabeth Kimani, Kobby Mensah, Stella Muthari, Francis Zotor, and Michelle Holdsworth. 2018. "Characterising the food and advertising environments of deprived neighbourhoods in African cities." Proceedings of the 8th Africa Nutrition Conference; Addis Ababa, Ethiopia.

Hafez, Navid. 2004. "Global marketing of tobacco: Uncovering the tobacco industry's international research agenda and young adult marketing strategies". In The 132nd Annual Meeting.

Harris, James Michael, Phillip R Kaufman, Stephen W Martinez, and Charlene C Price. 2002. "The US food marketing system, 2002: Competition, coordination, and technological innovations into the 21st century". Agricultural Economic Report Number 811 (No. 14732016-120693) DOI: 10.22004/ag.econ.34001

Hebden, Lana, Lesley King, and Bridget Kelly. 2011. "Art of persuasion: an analysis of techniques used to market foods to children." Journal of Paediatrics and Child Health, 47 (11):776-782.

Holdsworth, M., A. Laar, M. Green, R. Akparibo, F. Zotor, K. Mensah, and N. Bricas. 2019. "Dietary transition in Ghanaian cities: Leveraging evidence for policy and intervention to prevent diet-related non-communicable disease." Retrieved from https://scharr.dept.shef.ac.uk/dfc/communications/reports-and-policy-briefs/

Isgor, Zeynep, Lisa Powell, Leah Rimkus, and Frank Chaloupka. 2016. "Associations between retail food store exterior advertisements and community demographic and socioeconomic composition." Health \& Place, 39:43-50.

Jenkin, G, N Madhvani, L Signal, and S Bowers. 2014. "A systematic review of persuasive marketing techniques to promote food to children on television." Obesity Reviews, 15 (4):281-293.

Jernigan, David, Jonathan Noel, Jane Landon, Nicole Thornton, and Tim Lobstein. 2017. "Alcohol marketing and youth alcohol consumption: a systematic review of longitudinal studies published since 2008." Addiction, 112:7-20.

Kelly, Bridget, Michelle Cretikos, Kris Rogers, and Lesley King. 2008. "The commercial food landscape: outdoor food advertising around primary schools in Australia." Australian and New Zealand Journal of Public Health, 32 (6):522-528.

Kelly, Bridget, Jason CG Halford, Emma J Boyland, Kathy Chapman, Inmaculada BautistaCastaño, Christina Berg, Margherita Caroli, Brian Cook, Janine G Coutinho, and Tobias Effertz. 2010. "Television food advertising to children: a global perspective." American Journal of Public Health, 100 (9):1730-1736.

Kumi, I , and A Laar. 2020. "Healthiness of foods and beverages advertised on Ghanaian Television Networks Targeting Children". World Public Health Nutrition Congress 2020; Brisbane, Australia.

Labonté, Marie-Ève, Theresa Poon, Branka Gladanac, Mavra Ahmed, Beatriz FrancoArellano, Mike Rayner, and Mary R L'Abbé. 2018. "Nutrient profile models with 
applications in government-led nutrition policies aimed at health promotion and noncommunicable disease prevention: a systematic review." Advances in Nutrition, 9 (6):741-788.

Lane, K, and Kevin. 2001. "Mastering the marketing communications mix: Micro and macro perspectives on integrated marketing communication programs." Taylor \& Francis.

Larson, Nicole, and Mary Story. 2009. "A review of environmental influences on food choices." Annals of Behavioral Medicine, 38(1), 56-73.

Maher, Anthony, Nick Wilson, and Louise Signal. 2005. "Advertising and availability of'obesogenic'foods around New Zealand secondary schools: a pilot study." The New Zealand Medical Journal, 118 (1218).

Manyema, Mercy, Lennert J Veerman, Lumbwe Chola, Aviva Tugendhaft, Benn Sartorius, Demetre Labadarios, and Karen J Hofman. 2014. "The potential impact of a 20\% tax on sugar-sweetened beverages on obesity in South African adults: a mathematical model." PloS One, 9 (8):e105287.

Monteiro, Carlos A, Geoffrey Cannon, Renata Levy, Jean-Claude Moubarac, Patricia Jaime, Ana Paula Martins, Daniela Canella, Maria Louzada, and Diana Parra. 2016. "NOVA. The star shines bright." World Nutrition, 7 (1-3):28-38.

Moore, David, and Sara Konrath. 2014. "When Food Advertising Triggers Salivation: the Role of Positive Affectivity on Appetitive Craving and Eating Intentions." ACR North American Advances.

Nash, Cathriona, and Serge Basini. 2012. "Pester power: it's all in "the game”." Young Consumers,13 (3):267-283. doi: 10.1108/17473611211261665.

Nestle, Marion, and David S Ludwig. 2010. "Front-of-package food labels: public health or propaganda?" Jama, 303 (8):771-772.

Osei-Assibey, George, Smita Dick, Jennie Macdiarmid, Sean Semple, John J Reilly, Anne Ellaway, Hilary Cowie, and Geraldine McNeill. 2012. "The influence of the food environment on overweight and obesity in young children: a systematic review." BMJ Open, 2 (6).

PAHO. 2016. Nutrient Profile Model. Washington DC: PAHO; Accessed on 24 June 2020 at https://iris.paho.org/handle/10665.2/18621

Pechmann, Cornelia, Linda Levine, Sandra Loughlin, and Frances Leslie. 2005. "Impulsive and self-conscious: Adolescents' vulnerability to advertising and promotion." Journal of Public Policy \& Marketing, 24 (2):202-221.

Sadeghirad, B, T Duhaney, S Motaghipisheh, NRC Campbell, and BC Johnston. 2016. "Influence of unhealthy food and beverage marketing on children's dietary intake and preference: a systematic review and meta-analysis of randomized trials." Obesity Reviews, 17 (10):945-959.

Sally, Mackay, Molloy Janine, and Vandevijvere Stefanie. 2017. INFORMAS protocol: Outdoor advertising (school zones). The University of Auckland. Journal contribution. https://doi.org/10.17608/k6.auckland.5701102.v2

Scully, Paul, Orlaith Reid, Alan Macken, Mark Healy, Jean Saunders, Des Leddin, Walter Cullen, Colum Dunne, and Clodagh S O’Gorman. 2016. "Food and beverage cues in children's television programmes: the influence of programme genre." Public Health Nutrition, 19 (4):616-624.

Smith, Rachel, Bridget Kelly, Heather Yeatman, and Emma Boyland. 2019. "Food marketing influences children's attitudes, preferences and consumption: A systematic critical review." Nutrients, 11 (4):875.

Swinburn, Boyd, Ian Caterson, Jaap C Seidell, and W Philip T James. 2004. "Diet, nutrition and the prevention of excess weight gain and obesity." Public Health Nutrition, 7 (1a):123-146. 
Swinburn, Boyd, and Garry Egger. 2002. "Preventive strategies against weight gain and obesity." Obesity Reviews, 3 (4):289-301.

University of Ghana. 2012. "Policy regulating the placement of advertisement”. Accessed on 27 June 2020 at https://www.ug.edu.gh/paddocs/PolicyRegulatingthePlacementofAdvertisement.pdf

WHO. 2010. "Set of recommendations on the marketing of foods and non-alcoholic beverages to children. Geneva, World Health Organization; 2010. Accessed on 24 June 2020 at https://www.who.int/dietphysicalactivity/publications/recsmarketing/en/

WHO. 2015. WHO Regional Office for Europe nutrient profile model. Acessed on 24 June 2020 at https://www.euro.who.int/en/health-topics/diseaseprevention/nutrition/publications/2015/who-regional-office-for-europe-nutrientprofile-model-2015

WHO. 2018a. "Noncommunicable diseases - Fact sheet. Accessed on 20 April 2020 at https://www.who.int/news-room/fact-sheets/detail/noncommunicable-diseases

WHO. 2018b. "Noncommunicable diseases country profiles 2018. Accessed on 20 April 2020 at https://apps.who.int/iris/bitstream/handle/10665/274512/9789241514620eng.pdf

WHO. 2018c. "Nutrient profiling. Accessed 24 June 2020 http://www.who.int/nutrition/topics/profiling/en/

WHO. 2020a. "Healthy Diet - Fact sheet. Accessed on 24 April 2020 at https://www.who.int/news-room/fact-sheets/detail/healthy-diet

WHO. 2020b. Noncommunicable diseases progress monitor 2020. Geneva: World Health Organization; 2020. Licence: CC BY-NC-SA 3.0 IGO. Accessed May 202020 at https://www.who.int/publications-detail/ncd-progress-monitor-2020.

WHO Regional Office of Africa. 2014. "Noncommunicable diseases. Accessed on 20 April 2020 at https://www.afro.who.int/health-topics/noncommunicable-diseases

Wilson, Rick T, and Brian D Till. 2011. "Effects of outdoor advertising: Does location matter?" Psychology \& Marketing, 28 (9):909-933. 